The accents corresponding to these two tendencies are seen in many pertinent agrochemical studies: the quality of biological products being emphasized in the industrially developed countries and their quantity as a first priority in the less developed countries.

The published proceedings of the Congress deserve careful study by specialists in order to digest and utilize fully the wealth of scientific and technical information contained in the multitude of component reports.
Victor Abramovich Kovda, Corresponding Member $\&$

B. G. Rozanov

Academy of Sciences of the USSR

Scientific Council on Problems of Soil Science and Reclamation of Soils

c/Department I, 11 Fersman Street

Moscow 117 312, USSR.

\title{
The Importance for Rural Regions of Hunting and Shooting Game*
}

A report by the Parliamentary Assembly's Committee on Agriculture, adopted in July, proposes a better understanding of hunting and shooting. Starting with the public debate raging in many Council of Europe member states on the future of shooting game, it goes on to show that hunting may well be poorly understood owing to a failure to appreciate its essential role in preserving a wide and balanced variety of species and hence in environmental protection in general. The report calls for measures to improve the training of hunters, for intensified international cooperation, and for a more open and fruitful dialogue between hunters, farmers, foresters, and the general public, as to how their various interests can best be reconciled.

\footnotetext{
* Having been accustomed to hunting with hounds and, particularly, shooting game in our youth, we have ventured to include both activities - as environmentally desirable when properly controlled - in this title, although the Council of Europe did not so distinguish them in their note. $-E d$.
}

There have been many instances which bear witness to the desire of the majority of hunters to continue to act as managers of Nature, for example the purchase and management of a large area in south-west France and a campaign for birds of prey run by Italian hunters. At the international level, the Council of Europe's Code of Conduct for Hunters has been positively received, and an international seminar on the protection of the environment as a factor of economic development in rural areas will be held at the Palais de l'Europe in the spring of 1988 . Training for hunters will continue in order to put a stop to offences against legal and moral codes.

NEWSLETTER-NATURE AND ENVIRONMENT
Council of Europe
BP 431 R6
67006 Strasbourg, Cedex
France.

\section{Food Production and Agricultural Development up to Year 2000}

Although the world's farmers are growing more food each year and the alarming increase in world population is starting to slow down everywhere except in Africa, the 'unnecessary tragedy' for widespread hunger still remains, according to the updated 1987 edition of the Food and Agriculture Organization's (FAO) study, Agriculture: Toward 2000. This 263-pages' study, presented to FAO's recent biennial Conference, outlines crucial options for national, regional, and global, policymakers, for increasing food production. It states that 'the outstanding fact in food and agriculture is that the past 25 years have brought a better-fed world despite an increase of 1.8 [thousand millions] in World population'.

But as the FAO Director-General emphasizes in the Foreword, the general improvement in nutrition for the bulk of the world's people still excluded millions of the very poor. "Against a substantial achievement of a more ample diet for the majority of the world's population', he states, 'food supplies per caput in the low-income countries other than China were not significantly different in 1983-1985 from those of 15 years earlier.'

The study foresees that the number of seriously undernourished people in the world - those with food intakes of less than $40 \%$ above the basal metabolic rate (roughly 1,520 calories)-could rise somewhat, from the present 510 millions to 530 millions, though their percentage of the total population would decline significantly. Unforeseen natural or Man-made calamities could push the number much higher, however.
Also, world economic trends work against the chances of many developing countries, especially the very poor ones, to improve the living standards of their citizens, some of whom may face outright starvation. Thus in analysing the food production figures in 94 'developing' countries, the study found that the shadow of famine had tended to diminish in Asia - particularly in China. Indeed the outlook for most of Asia over the period to the end of the century looks promising, according to the study.

But other regions are not so fortunate, and the study points out that 'the overall economic crisis of the last few years virtually arrested the rising trend of calorie consumption in Latin America and, together with the effects of drought and deterioration of agricultural conditions, reduced consumption in sub-Saharan Africa; per caput food availabilities were lower in 1983-1985 than in 1979-1981 in 37 of the 94 developing countries. Of the 37 countries, 24 were in sub-Saharan Africa'.

While hailing the contribution of technology to the rise of food production over the past quarter-century, the study urged that much more be done to direct research towards helping the 2 thousand million or so of small farmers whose average income is in the area of $\$ 75$ a year. They are the rural poor who have been largely bypassed by progress. Many of the Earth's $c$. 500 millions of seriously undernourished people are, paradoxically, farmers or fishermen.

UNITEd Nations' INTERNATIONAL ReVIEW Palais des Nations

1211 Geneva 10

Switzerland. 